\title{
Technology Based Model of a Mobile Knowledge as a Service to Facilitate Education Community
}

\author{
https://doi.org/10.3991/ijim.v15i24.27335 \\ Ashraf Badawood $\left.{ }^{(}\right)$, Hamad AlBadri \\ University of Jeddah, Jeddah, Saudi Arabia \\ ambadawood@uj .edu.sa
}

\begin{abstract}
Technological enhancements as well as the demand of students to access learning information on time and quickly has resulted to the development of e-learning across the world. Mobile learning has been adopted by most learning institution as a mobile technology that allows learners to access learning materials and share information among themselves and respective educators easily and quickly. This article discusses the intention of users in learning environment adopting m-learning, their perceptions as well as factors that hinder implementation of m-learning in the gulf region. Effective mobile technology adoption also enhances knowledge management through mobile applications that allow information capture, storage, retrieval and sharing. This study uses systematic literature review to collect information from post 2017 studies previous conducted by other researchers. Articles were searched through highly ranked databases from which 657 journals were identified. After the screening and eligibility assessment, 24 journals were retrieved. The back and forward search retrieved 4 more journals bringing the total to 28 journals that were included in the study. Based on this information, a conceptual model is developed to help assess the m-learning perceptions, adoption intentions and factors influencing its adoption among learning institutions in the gulf region. This model is built based on the Theory of Planned Behavior and Unified Theory of Acceptance and Use of Technology. Based on the developed model, main constructs such as performance expectancy, effort expectancy and social influence are greatly impacted by other factors like learner's creativity and mobility.
\end{abstract}

Keywords-M-learning, mobile technology, knowledge management, performance expectancy, effort expectancy

\section{Introduction}

The increased availability and affordability of mobile devices as well as wireless networks provide more opportunities for users to acquire knowledge. Recently, learning has taken a dramatic shift from traditional to E-learning. Mobile learning is the current technology that has widely been adopted to rapidly drive E-learning based on individual mobile devices with no restrictions on time or location. According to Al-Emran \& Salloum [1] implementation of technology across several sectors resulted to use of mobile devices in the learning sector. Such new learning devices present users 
with both challenges alongside diverse opportunities depending on the environment. M-learning has been described by different authors as a learning approach which permits learners to access learning materials through their mobile phones anytime [2].

Given the widespread of mobile phones among Arab students, a study by [3] indicated that M-learning is widely accepted since it addresses mobility in different ways including mobility of technology, learners as well as educators. Research by [4] concluded that adoption of M-learning with regards to user acceptance as well as satisfaction is likely to enhance user interaction as well as their learning experience. Even so, [5] note that their lacks sufficient research on key aspect that that influence use of m-learning in different countries. Authors in [6] indicate that in majority of Arab Gulf countries including Kuwait, Oman, Saudi Arabia and United Arab Emirates, there is a rapid increase in wireless internet connection that has become a significant determiner of mobile leaning. In countries like Saudi Arabia, m-learning has become a new normal for majority of students. Authors in [4] found out that mobile phone subscribers in 2017 were around 21.18 million in Saudi Arabia. However, several factors prove to be investable which may interrupt m-learning and delay the assured revolution. For instance, [6], carried out a study on 29 mobile phone technology manufacturers, business as well as education suppliers and concluded that mobile based technologies are well adopted in commercial establishments but very few learning institutions have embraced it in the Gulf region.

Also, [7] affirm that although mobile learning has proven its greatness in learning by offering opportunities as well as avenues for enhancement of knowledge sharing practices among higher education learners, Arab Gulf Countries generally lack knowledge sharing activities among learners. Several studies have also indicated that there is insufficient research regarding adoption of mobile phone technologies for the purposes of sharing knowledge. Another study conducted by [8], with regards to the Theory of Planned Behavior concluded that the adoption of mobile learning in UEA is to a large extent influenced by user's attitude, the subjective norm as well as perceptions towards behavioral control. Knowledge management within learning institutions plays a crucial role towards the institution's success. According to [9], advantages of operative KM to an institution's competitive advantage include aspects such as streamlined decision making, quick response to issues as well as enhanced problem. The main issues related to $\mathrm{KM}$ is knowledge conversion among learners and operation into knowledge that can be easily and widely available to other users. A study by [10] concluded that information technologies continue to be essential influencers of KM systems due to their ability to capture, store, transform and also disseminate knowledge.

\subsection{Research problem}

Use of mobile devices has become ubiquitous across most communities. However, the awareness and readiness to embrace mobile technologies for competence learning is not widespread in the Gulf region thus the need for further exploration. Most Arab counties are experiencing challenges that have for long been associated with acceptance as well as adoption of M-learning. As such, there is little research on factors that enhance m-learning. This study therefore proposes a conceptual framework model of mobile technology knowledge based on previous studies. This model will incorporate 
the Theory of Planned Behavior and Unified Theory of Acceptance and Use of Technology to assess the intentions of using mobile devices as well as software to transfer knowledge. Therefore, the following research question will be answered by this study:

What are key influencers of technology-based model of a mobile knowledge as a service to facilitate learning in the gulf region?

\subsection{Significance of the study}

This research aims at developing a new conceptual framework that can provide education policy makers with a basis for planning as well as implementing effective m-learning programs. Also, this framework can be adopted to enhance knowledge management among learning institutions to understand how certain challenges can be addressed.

\subsection{Limitation of the study}

First, some reviews failed to provide summaries of the studies used and some heavily relied on few databases to identify potential studies. Such studies were rejected thus reducing the numbers of journals used for this study. However, this study effectively used inclusion and exclusion criteria to singly assess previous studies to collect rich data for this research.

\subsection{Operational definition}

Mobile technology, m-learning and knowledge management are the chief variables for this research. Mobile technology in this study refers to portable two-way interruption devices, computing devices as well as networking technology with the ability to link users. M-learning is adopted as a form of content which is either developed and/ or consumed through mobile devices. Lastly, knowledge management is adopted from learning institution practices perspective including creating, sharing as well as transferring knowledge among users inside and outside the learning institutions.

\section{Research method and procedures}

This study used systematic literature review which involved four distinct stages [11]. First, the author only included studies that provided a clear guidance regarding literature review and also, literature reviews that exactly answered this study's research question were discarded. That is, studies that were included in this research by the author had a wide range of aspects on mobile technology, m-learning and knowledge management in the learning community. The author used identification approach to seek for highly ranked journals by mainly searching through the databases and other reliable sources. The author searched for researches on m-learning within Arab Gulf countries using different databases including IEEE, Google Scholar as well as Science Direct. In the process, the author also scanned references provided by potential studies in order to access more significant researches. To achieve this, key words used to retrieve relevant articles included "m-learning", "mobile learning adoption" as well as 
"mobile learning services". The search was then narrowed to the Gulf region to include several countries like Oma, Kuwait, UAE, Bahrain and also Saudi Arabia. Also, this search was specified to learning institutions. Moreover, this study restricted the search to post 2017 highly ranked journals to ensure that results are built on the most recent studies.

Thirdly, after inclusion and exclusion, selected journals were recorded in a table and screened for their eligibility and relevancy to the topic under study. The author then screened the list and discarded duplicate articles. Also, this study conducted a parallel assessment to seek for discrepancy after which they were effectively resolved. A list of full-text journals was retrieved for a quality assessment. Fourthly, collected journals related to adoption of m-learning, mobile learning adoption and mobile learning services were assessed with regards to the including and exclusion criteria for eligibility. The author therefore considered journals that focused on investigating user perception of mobile learning from student, instructor and staff's point of view from diverse learning institutions in the gulf region precisely published post 2017. Also, all journals used were peer reviewed. Additionally, journals that focused on evaluating or comparing mobile learning with the e-learning system were discarded. Journals that only investigated implementation of m-learning technology stage, training as well as technical factors were also discarded. Therefore, this research on dwelt on highly ranked journals which were also referenced properly.

The author also ran another independent parallel assessment on quality as well as eligibility after which discrepancies were also appropriately resolved. And more journals were excluded for different reasons including lack of precise literature review of topic under investigation, lack of clear direction of the methodology and also, some journals lacked full text. Lastly, this study also conducted a back and forward search to collect more literature for more effective results and conclusion. Upon assessment of the articles' reviews, some journals were considered eligible by author based on their adherence to required referencing.

The first search retrieved 657 journals. 51 journals were removed as they were duplicates. After removal of duplicates, titles and abstracts 606 journals were screened and 512 were discarded. The remaining 94 full-text journals associated with m-learning adoption were assessed against the criteria of inclusion and exclusion and 70 more journals were removed for not meaningfully relating with m-learning in education utilization leaving 24 journals. To increase the number of research for effective literature review, this study also conducted a back and forward search from which 4 more journals were retrieved bringing the total number of promising journals to 28 as shows in Figure 1.

\section{$3 \quad$ Results and discussions}

Several studies have indicated that m-learning solutions in the gulf region are adopted differently. According to [12-13], Kuwait and Oman are more cautious of adopting mobile learning while Iraq and Yemen are the least as compared to the rest of the region. Moreover, in the recent past, some countries like Saudi Arabia have gradually moved towards adopting utilization of m-learning due to improved information communica- 
tion technology. Several studies have also been conducted to assess key aspects influencing m-learning adoption if different regions. Authors such as [14] have frequently mentioned factors like expected performance, expected effort as well as social aspects to have a significant effect on adoption of m-learners among most learners. Based on literature some region like Kuwait have been less researched although [15], mentions that understanding cultural as well as social issues can permit development of improved m-learning plan to assist tutors to effectively incorporate mobile learning in teaching and learning. Another study by [16], concluded that satisfaction among students on the use of m-learning in the Middle East is influenced by the internet speed and usability skills among others. Authors in [12] opine that instructors as well as students possess diverse positive perceptions regarding $\mathrm{m}$-learning due to video-related social media applications as well as their acquaintance
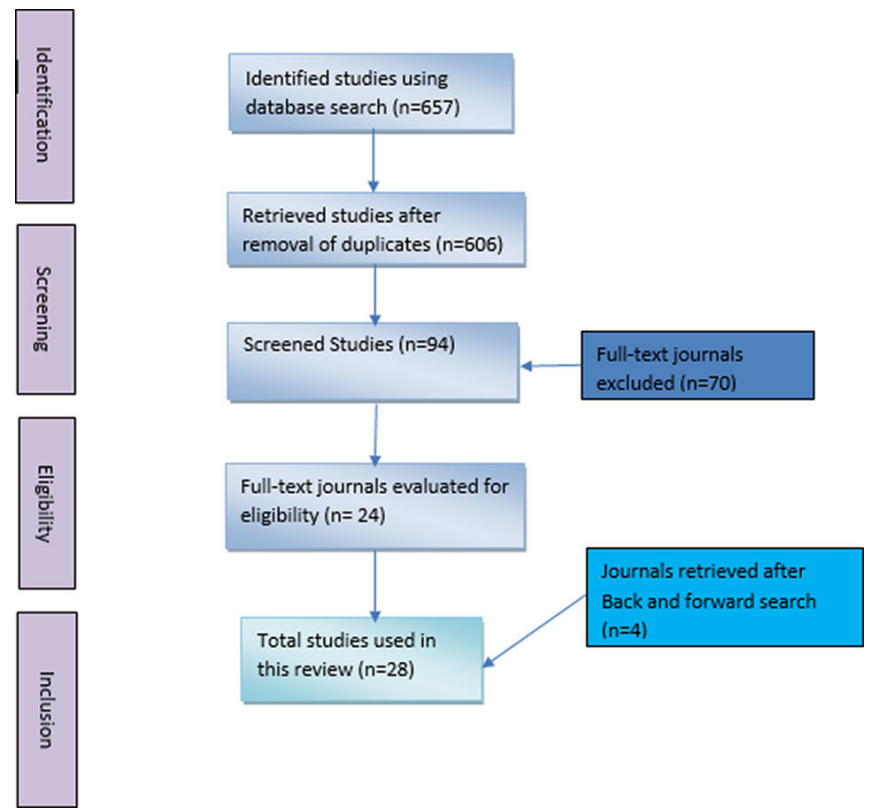

Fig. 1. Systematic review stages

with the mobile devices. Also, although there is a speedy development of m-learning technology in Oman, very few researchers have been conducted to assess influencers of m-learning adoption. However, a study by [11] in Oman to investigate factors influencing m-learning adoption, awareness as well as attitudes among university students concluded that qualifications as well as the mobile device brand were major factors of influence.

Another study by [3], indicated that student's knowledge as well as perceptions impacted adoption of m-learning. Study investigated in [17] also found out that the ease of use, and suitability were also among factors that affected utilization of m-learning among learners in Oman. According to a study conducted by [12], different aspects such as being in possession of smartphone, level of education and academic rank 
influence learner's attitude towards m-learning in universities. Authors in [18] affirmed that issues related to awareness of m-learning, the mode of m-learning, self-confidence as well as computer competence need to be highly upheld and carefully executed by institutions to warrant effective adoption well as reliability of m-learning. Authors in [19] also carried out a research to assess present trends, opportunities as well as skills and the roles they play in m-learning implementation and concluded that, technology experience, type of mobile device and the ability to use social media are among essential aspects to understand and improve instructors' efficiency and also enhance motivational aspects within learning institutions.

Authors in [20] conducted a study in universities in Bahrain on their perceptions towards the adopting m-learning and concluded that the ease of use, effectiveness and facilitation conditions were key factors. According to these findings, it can be argued that very little attention has been given towards the role of m-learning within most universities in Bahrain. Authors in [21] found out that the impact of anxiety on one's intention to adopt m-learning among most students in the universities in Yemen is a key aspect. In another study on university students in Iraq, utilization of m-learning was affected by social factors, performance expectations as well as self-management learning. Social factors have been found by most researchers to contribute towards effectiveness of the adopted m-learning. Authors in [6] conducted a research on factors affecting implementation as well as adoption on m-learning solutions within countries in the gulf region as summarized findings in Figure 2. Basing their research on twenty-four articles, this study concluded that system service accessibility, technical competency, IT infrastructure and management are most addressed issues as influencers of m-learning adoption.

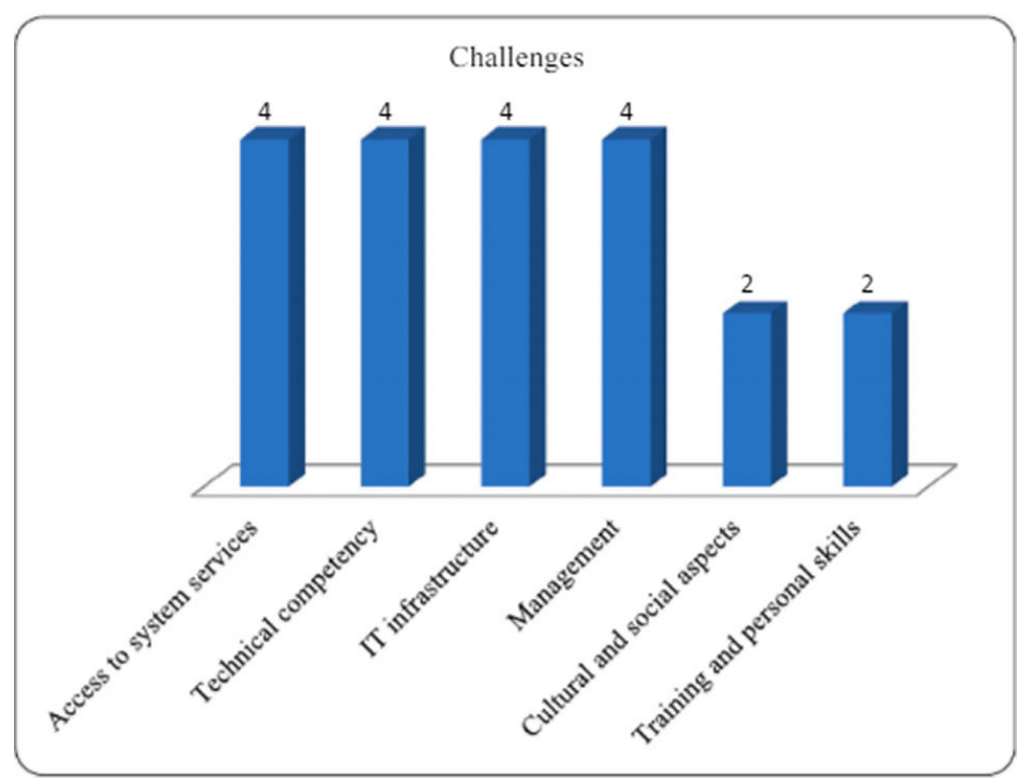

Fig. 2. Factors affecting m-learning adoption [9] 
The increased use of mobile technology in the education sector in the gulf region has continued to show a great potential and has become a key driver of adoption of m-learning across most universities. In another study, [22] highlighted that some of the positive attributes behind using mobile technologies for learning include increased student support, enhanced accessibility to learning information and more timely and unrestricted learning. Authors in [23] found out that by enhancing he capability of mobile devices and increasing mobility as well as flexibility, learning institutions in the gulf region allow students to freely access learning materials and increases their accessibility to learning information. According to [24], information technology in the middle east is the significant enabler of knowledge management systems through their ability to enable capture, storage, transformation as well as dissemination of knowledge. Additionally, [25], the emergence of ICT including mobile devices as essential techno-management tools for knowledge management practices to improve level and quality of sharing and using knowledge has become widespread in the Middle East. Authors in [26] assert that the general aim of KM is to prompt and integrate tacit knowledge possessed by an individual with available explicit knowledge to direct one's development and well as learning institutions.

To increase knowledge as an asset, learning institutions develop frameworks that focus on increasing knowledge sharing as well as collaboration. As such, [27] point that there Is need for institutions to adopt systematic knowledge practices to link learners, educators and external bodies among other users. In relation, mobile learning continues to prove its relevancy in providing better opportunities for collaboration as well as interaction for efficient learning outcomes in and/or out of learning environment. According to [28], mobile tools for KM have been adopted by most universities in UAE to offer technological basis for education service delivery as well as facilitating more convenient and complex interactions among learners and between them and their respective teachers. Modern students are in need of novel ways of learning and more effective channels of communication for creation as well as knowledge management [29]. In response, a study by [30] concluded that mobile technology addresses learners changing demands through quick and ease check of work accuracy. Also, this study indicated that mobile devices have enable university student in Bahrain to share and retrieve knowledge information any time. Authors in [31] opines that KM toolkit apps offered through mobile devices allows students in universities within UAE to enhance notetaking, structure, aggregate information as well as share knowledge. This study also found out that students are able to develop folders to store, edit and also share information while still engaging in collaborative learning process. Also, mobile devices adopted for learning offer learners with improved chances to easily address the gaps in their knowledge. Authors in [32] found out that using mobile devices to retrieve, store as well as exchange academic information by students including videos and images are also influencers of KM outcomes.

Authors in [33] conducted a study and concluded that the core aspect concerning the impact of mobile technologies on learning in Iraq learning institutions including mobile technology effectiveness on KM was thought by students to be determined by how the technology supports accessibility to learning materials students. This study also revealed that leaners believed that it was easier for them to access learning materials at their own pace without engaging lecturers when using mobile technologies. 
Knowledge sharing has also continued to be perceived by previous literature as a core objective of KM. Communication efficacy to enable construction of knowledge as well as collaborative learning was found to shape learner's perceptions of incorporating mobile technologies in learning practices [34].

As indicated in Figure 3, this study has incorporated the theory of planned behavior and the Unified Theory of Acceptance and Use of Technology to develop a new model for using mobile technology in learning institutions. This study has incorporated student's mobility and innovativeness in the proposed model as factors that may influence key constructs including performance expectancy, effort expectancy as well as social influence. According to [35] peer influence plays a key role in determining learners' behavioral intentions to adopted mobile technologies. Table 1 presents a list of the reviewed studies [37].

Table 1. List of reviewed articles

\begin{tabular}{|l|c|c|c|c|}
\hline \multicolumn{1}{|c|}{ Author(s) } & $\begin{array}{c}\text { Mobile/ } \\
\text { l-learning } \\
\text { Adoption }\end{array}$ & $\begin{array}{c}\text { Technology } \\
\text { Acceptance }\end{array}$ & $\begin{array}{c}\text { Mobile Use } \\
\text { Readiness }\end{array}$ & $\begin{array}{c}\text { Knowledge } \\
\text { Management }\end{array}$ \\
\hline Kumar \& Moral (2019) [17] & $\checkmark$ & & & \\
\hline Isaac et al., (2019) [33] & $\checkmark$ & $\checkmark$ & & $\checkmark$ \\
\hline Alshehri \& Cumming (2020) [32] & $\checkmark$ & $\checkmark$ & & \\
\hline Kuo, Belland \& Kuo (2017) [34] & $\checkmark$ & & & \\
\hline Al-Emran \& Shaalan (2017) [7] & & $\checkmark$ & & $\checkmark$ \\
\hline Alsswey \& Al-Samarraie (2019) [6] & $\checkmark$ & $\checkmark$ & & $\checkmark$ \\
\hline Al-Kindi \& Al-Suqri (2017) [23] & $\checkmark$ & & & \\
\hline Al-Emran \& Mezhuye (2019) [26] & $\checkmark$ & & & $\checkmark$ \\
\hline Botero et al., (2019) [35] & & $\checkmark$ & & \\
\hline Razzaque (2020) [31] & $\checkmark$ & & $\checkmark$ & \\
\hline $\begin{array}{l}\text { Al-Adwan, Al-Adwan \& Berger } \\
\text { (2018) [4] }\end{array}$ & $\checkmark$ & & & \\
\hline Thongsri et al., (2018) [5] & $\checkmark$ & & & \\
\hline Khan et al., (2019) [36] & $\checkmark$ & & & \\
\hline Al-Emran \& Salloum (2017) [7] & & $\checkmark$ & $\checkmark$ & \\
\hline $\begin{array}{l}\text { Alshurideh, Al Kurdi \& Salloum } \\
\text { (2019) [8] }\end{array}$ & & $\checkmark$ & $\checkmark$ & \\
\hline David et al., (2017) [12] & & $\checkmark$ & & \\
\hline Alsswey et al., (2020) [13] & $\checkmark$ & $\checkmark$ & & \\
\hline $\begin{array}{l}\text { Bakhsh, Mahmood \& Sangi (2017) } \\
\text { [14] }\end{array}$ & $\checkmark$ & $\checkmark$ & & \\
\hline Ahmed \& Ghareb (2017) [16] & $\checkmark$ & & & \\
\hline Al-Hunaiyyan et al., (2017) [19] & $\checkmark$ & & & \\
\hline Al-Rahmi et al., (2019) [22] & & & & \\
\hline
\end{tabular}

(Continued) 
Table 1. List of reviewed articles (Continued)

\begin{tabular}{|l|c|c|c|c|}
\hline \multicolumn{1}{|c|}{ Author(s) } & $\begin{array}{c}\text { Mobile/ } \\
\text { I-learning } \\
\text { Adoption }\end{array}$ & $\begin{array}{c}\text { Technology } \\
\text { Acceptance }\end{array}$ & $\begin{array}{c}\text { Mobile Use } \\
\text { Readiness }\end{array}$ & $\begin{array}{c}\text { Knowledge } \\
\text { Management }\end{array}$ \\
\hline Uden, He (2017) [9] & & & $\checkmark$ & $\checkmark$ \\
\hline $\begin{array}{l}\text { Raudeliuniene, Albats \& Kordab } \\
\text { (2020) [25] }\end{array}$ & & $\checkmark$ & & $\checkmark$ \\
\hline Santoro et al., (2019) [10] & & & $\checkmark$ & \\
\hline Alrajawy et al., (2018) [21] & $\checkmark$ & $\checkmark$ & $\checkmark$ & \\
\hline Chang, Liu \& Huang (2017) [18] & $\checkmark$ & $\checkmark$ & & $\checkmark$ \\
\hline Qi \& Chau (2018) [29] & $\checkmark$ & & $\checkmark$ & \\
\hline Salloum at al., (2018) [28] & $\checkmark$ & & & \\
\hline
\end{tabular}

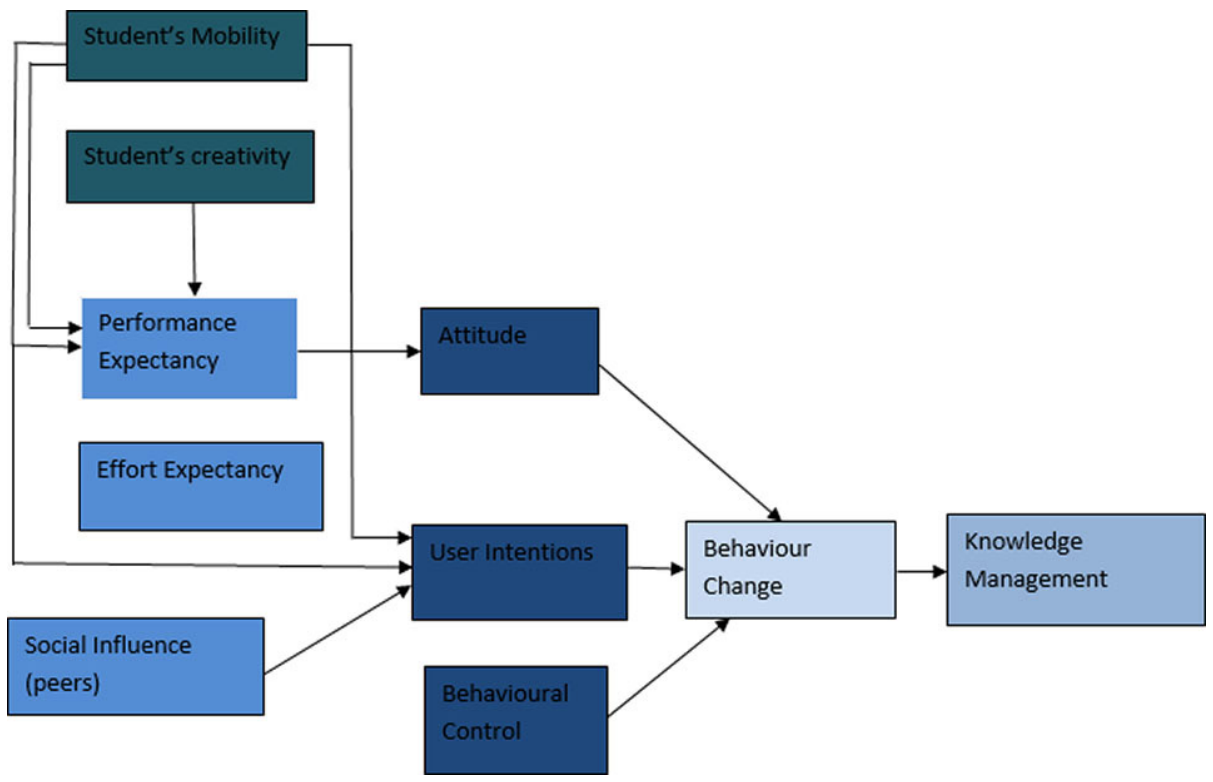

Fig. 3. Proposed model

\section{Conclusions}

This study focused on investigating learners' readiness and perceptions towards adopting mobile learning within countries in the gulf region. The study has reviewed the prospects as well as difficulties with adopting mobile technology in learning institutions in the gulf region. The author has adopted the UTAUT model and the Theory of Planned Behavior to develop a novel model that can be used to assess learner's readiness to adopt m-learning technology in learning institutions. This study helps 
learning institutions across the world to learn of prospects and challenges of introducing m-learning as an alternative to classroom learning. Also, this study offers a clear understanding on effective ways of integrating mobile technologies in learning programs to enhance knowledge management. Also, this model can be used by learners to assess whether or not mobile technology services provided to them should be discontinued, enhanced or replaced. Although, studies have indicated there are challenges and risks of adopting mobile technologies, they are overwhelmed by the benefits especially in a learning set up.

\section{$5 \quad$ References}

[1] Al-Emran, M., and Mezhuyev, V., Examining the effect of knowledge management factors on mobile learning adoption through the use of im-portance-performance map analysis (IPMA). In International Conference on Advanced Intelligent Systems and Informatics, October 2019. Springer, Cham, pp. 449-458. https://doi.org/10.1007/978-3-030-31129-2 41

[2] Khan, M. S. H., Abdou, B. O., Kettunen, J., and Gregory, S. (2019). A phenomeno-graphic research study of students' conceptions of mobile learning: An example from higher education. Sage Open, 9: 2158244019861457. https://doi.org/10.1177/2158244019861457

[3] Al-Adwan, A. S., Al-Madadha, A., and Zvirzdinaite, Z. (2018). Modeling students' readiness to adopt mobile learning in higher education: An empirical study. In-ternational Review of Research in Open and Distributed Learning, 19(1). https://doi.org/10.19173/irrodl. v19i1.3256

[4] Al-Adwan, A. S., Al-Adwan, A., and Berger, H. (2018). Solving the mystery of mobile learning adoption in higher education. International Journal of Mobile Communications, 16 : 24-49. https://doi.org/10.1504/IJMC.2018.088271

[5] Thongsri, N., Shen, L., Bao, Y., and Alharbi, I. M. (2018). Integrating UTAUT and UGT to explain behavioural intention to use M-learning: A developing country's perspective. Journal of Systems and Information Technology. https://doi.org/10.1108/JSIT-11-2017-0107

[6] Alsswey, A., and Al-Samarraie, H. (2019). M-learning adoption in the Arab gulf countries: A systematic review of factors and challenges. Education and Infor-mation Technologies, 24: 3163-3176. https://doi.org/10.1007/s10639-019-09923-1

[7] Al-Emran, M., and Salloum, S. A. (2017). Students' Attitudes Towards the Use of Mobile Technologies in e-Evaluation. Int. J. Interact. Mob. Technol., 11: 195-202. https://doi. org/10.3991/ijim.v11i5.6879

[8] Alshurideh, M., Al Kurdi, B., and Salloum, S. A., Examining the main mobile learning system drivers' effects: A mix empirical examination of both the Expectation-Confirmation Model (ECM) and the Technology Acceptance Model (TAM). In International Conference on Advanced Intelligent Systems and Informatics, October 2019, Springer, Cham, pp. 406-417. https://doi.org/10.1007/978-3-030-31129-2 37

[9] Uden, L., and He, W. (2017). How the Internet of Things can help knowledge management: a case study from the automotive domain. Journal of Knowledge Management. https://doi. org/10.1108/JKM-07-2015-0291

[10] Santoro, G., Vrontis, D., Thrassou, A., and Dezi, L. (2018). The Internet of Things: Building a knowledge management system for open innovation and knowledge management capacity. Technological forecasting and social change, 136: 347-354. https://doi.org/10.1016/j. techfore.2017.02.034

[11] Følstad, A., and Kvale, K. (2018). Customer journeys: a systematic literature review. Journal of Service Theory and Practice. https://doi.org/10.1108/JSTP-11-2014-0261 
[12] David, S. A., Taleb, H., Scatolini, S. S., Al-Qallaf, A., Al-Shammari, H. S., and George, M. A. (2017). An exploration into student learning mobility in higher education among the Arabian Gulf Cooperation Council countries. International Journal of Educational Development, 55 : 41-48. https://doi.org/10.1016/j.ijedudev.2017.05.001

[13] Alsswey, A., Al-Samarraie, H., El-Qirem, F. A., and Zaqout, F. (2020). M-learning technology in Arab Gulf countries: A systematic review of progress and recommendations. Education and Information Technologies, 25: 1-13. https://doi.org/10.1007/s10639-019-10097-z

[14] Bakhsh, M., Mahmood, A., and Sangi, N. A. (2017). Examination of factors influencing students and faculty behavior towards m-learning acceptance. The International Journal of Information and Learning Technology. https://doi.org/10.1108/IJILT-08-2016-0028

[15] Al-Hunaiyyan, A., Al-Sharhan, S., and Alhajri, R. (2017). A New Mobile Learning Model in the Context of Smart Classroom Environment: A Holistic Approach. International journal of interactive mobile technologies, 11. https://doi.org/10.3991/ijim.v11i3.6186

[16] Ahmed, A. M., and Ghareb, M. I. (2017). Design a mobile learning framework for students in higher education. Journal of University of Human Development, 3: 288-296. https://doi. org/10.21928/juhd.20170315.15

[17] Kumar, S. R., and Moral, C. S. (2019). Attitude towards mobile learning in relation to academic performance of pre-teachers. ZENITH International Journal of Multidisciplinary Research, 9: 293-303.

[18] Chang, W. H., Liu, Y. C., and Huang, T. H. (2017). Perceptions of learning effectiveness in M-learning: scale development and student awareness. Journal of Computer Assisted Learning, 33: 461-472. https://doi.org/10.1111/jcal.12192

[19] Al-Hunaiyyan, A., Bimba, A. T., Idris, N., and Al-Sharhan, S. (2017). A cognitive knowledge-based framework for social and metacognitive support in mobile learning. Interdisciplinary Journal of Information, Knowledge \& Management, 12.https://doi.org/10.28945/3670

[20] Al-Emran, M., Mezhuyev, V., and Kamaludin, A. (2020). Towards a conceptual model for examining the impact of knowledge management factors on mobile learning acceptance. Technology in Society, 61: 101-247. https://doi.org/10.1016/j.techsoc.2020.101247

[21] Alrajawy, I., Isaac, O., Ghosh, A., Nusari, M., Al-Shibami, A. H., and Ameen, A. A. (2018). Determinants of Student's intention to use Mobile learning in Yemeni public universities: Extending the technology acceptance model (TAM) with anxiety. International Journal of Management and Human Science (IJMHS), 2: 1-9.

[22] Al-Rahmi, W. M., Yahaya, N., Aldraiweesh, A. A., Alamri, M. M., Aljarboa, N. A., Alturki, U., and Aljeraiwi, A. A. (2019). Integrating technology acceptance model with innovation diffusion theory: An empirical investigation on students' intention to use E-learning systems. IEEE Access, 7: 26797-26809. https://doi.org/10.1109/ACCESS.2019.2899368

[23] Al-Kindi, S. S., and Al-Suqri, M. N. (2017). Mobilizing learning: Using moodle and online tools via smartphones. International Journal of Knowledge Content Development \& Technology, 7: 67-86.

[24] Abualoush, S., Masa'deh, R., Bataineh, K., and Alrowwad, A. (2018). The role of knowledge management process and intellectual capital as intermediary variables between knowledge management infrastructure and organization performance. Interdisciplinary Journal of Information, Knowledge, and Management, 13: 279-309. https://doi.org/10.28945/4088

[25] Raudeliuniene, J., Albats, E., and Kordab, M. (2020). Impact of information technologies and social networks on knowledge management processes in Middle Eastern audit and consulting companies. Journal of Knowledge Management. https://doi.org/10.1108/ JKM-03-2020-0168

[26] Al-Emran, M., and Mezhuyev, V., Examining the effect of knowledge management factors on mobile learning adoption through the use of importance-performance map analysis (IPMA). In International Conference on Advanced Intelligent Systems and Informatics, October 2019, Springer, Cham, pp. 449-458. https://doi.org/10.1007/978-3-030-31129-2_ 41 
[27] Al-Emran, M., and Shaalan, K. (2017). Academics' awareness towards mobile learning in Oman. International Journal of Computing and Digital Systems, 6: 45-50. https://doi. org/10.12785/IJCDS/060105

[28] Salloum, S. A., Maqableh, W., Mhamdi, C., Al Kurdi, B., and Shaalan, K. (2018). Studying the social media adoption by university students in the United Arab Emirates. International Journal of Information Technology and Language Studies, 2: 83-95.

[29] Qi, C., and Chau, P. Y. K. (2018). Will enterprise social networking systems promote knowledge management and organizational learning? An empirical study. Journal of Organizational Computing and Electronic Commerce, 28: 31-57. https://doi.org/10.1080/1 0919392.2018.1407081

[30] Florenthal, B. (2019). Students' motivation to participate via mobile technology in the classroom: A uses and gratifications approach. Journal of Marketing Education, 41: 234-253. https://doi.org/10.1177/0273475318784105

[31] Razzaque, A. (2020). M-Learning Improves Knowledge Sharing Over e-Learning Platforms to Build Higher Education Students' Social Capital. SAGE Open, 10: 2158244020926575. https://doi.org/10.1177/2158244020926575

[32] Alshehri, A., and Cumming, T. M. (2020). Mobile Technologies and Knowledge Management in Higher Education Institutions: Students' and Educators' Perspectives. World Journal of Education, 10: 12-22. https://doi.org/10.5430/wje.v10n1p12

[33] Isaac, O., Abdullah, Z., Aldholay, A. H., and Ameen, A. A. (2019). Antecedents and outcomes of internet usage within organisations in Yemen: An extension of the Unified Theory of Acceptance and Use of Technology (UTAUT) model. Asia Pacific Management Review, 24: 335-354. https://doi.org/10.1016/j.apmrv.2018.12.003

[34] Kuo, Y. C., Belland, B. R., and Kuo, Y. T. (2017). Learning through blogging: Students' perspectives in collaborative blog-enhanced learning communities. Journal of Educational Technology \& Society, 20: 37-50.

[35] Botero, G. G., Questier, F., Cincinnato, S., He, T., and Zhu, C. (2018). Acceptance and usage of mobile assisted language learning by higher education students. Journal of Computing in Higher Education, 30: 426-451. https://doi.org/10.1007/s12528-018-9177-1

[36] Khan, M. S. H., Abdou, B. O., Kettunen, J., and Gregory, S. (2019). A phenomenographic research study of students' conceptions of mobile learning: An example from higher education. Sage Open, 9: 2158244019861457. https://doi.org/10.1177/2158244019861457

[37] Quasim, M. T., Alhuwaimel, S., Shaikh, A., Asiri, Y., and Rajab, K. et al. (2021). An Improved Machine Learning Technique with Effective Heart Disease Prediction System. CMC-Computers, Materials \& Continua, 69: 4169-4181. https://doi.org/10.32604/ cmc.2021.015984

\section{Authors}

Ashraf Badawood, College of Business, MIS, University of Jeddah, Jeddah, Saudi Arabia.

Hamad AlBadri, College of Business, MIS, University of Jeddah, Jeddah, Saudi Arabia. E-mail: halbadri@uj.edu.sa

Article submitted 2021-09-05. Resubmitted 2021-10-12. Final acceptance 2021-10-13. Final version published as submitted by the authors. 